\title{
Penilaian Postur Kerja Menggunakan Metode Quick Exposure Checklist (QEC) di IKM Tahu Sari Murni
}

\author{
Dian Pembayung*), Bambang Suhardi, Rahmaniyah Dwi Astuti \\ Program Studi Teknik Industri, Fakultas Teknik, Universitas Sebelas Maret Jl.Ir.Sutami 36A Surakarta 57126 \\ Indonesia
}

\section{DOI: 10.20961/performa.17.1.18984}

\begin{abstract}
Abstrak
IKM (Industri Kecil Menengah) Tahu Sari Murni merupakan industri pengolahan tahu dengan target produksi mencapai 250 loyang per hari. Aspek ergonomi pekerja dan stasiun kerja yang kurang menjadi perhatian menyebabkan munculnya postur tidak alamiah yang dapat menyebabkan munculnya gangguan muskuloskeletal dan menurunkan performa pekerja. Bekerja dalam posisi berdiri menghabiskan energi sekitar 10\% -15\% dibandingkan dalam posisi duduk. Apabila postur berdiri dilakukan dalam waktu lama, maka kesehatan pekerja dapat terganggu dan dapat mempengaruhi aktivitas produksi. Berdasarkan observasi, hampir seluruh pekerja bekerja pada posisi berdiri dengan postur janggal seperti memutar, bengkok kesamping, dan berdiri selama 7-8 jam. Dengan demikian, penilaian risiko postur kera perlu dilakukan untuk menentukan risiko kerja yang dialami oleh pekerja menggunakan metode QEC. Hasil menunjukkan hanya pada stasiun pencucian yang termasuk dalam kategori "aman" dimana enam stasiun lain berada pada level 3 yang menandakan bahwa diperlukan adanya perbaikan.
\end{abstract}

Kata kunci: Postur Janggal, Gangguan Muskuloskleteal, NBM, QEC

\begin{abstract}
SME (Small and Medium Enterprise) Tahu Sari Murni is a tofu producing industry with a production target up to 250 pans a day. The aspects of ergonomics in workers and work stations which is less-attention lead to the emergence of unnatural postures that potentially cause musculoskeletal disorders and decreased worker performance. Working in a standing position consumes energy by 10\% -15\% compared to work done in a sitting position. If the posture stays for a prolonged period, then the health of the worker may be disrupted and affect production activity. Based on observastions most of workers, working on a standing position with awkward posture such as lifting, bending, and standing for 7-8 hours. Therefore, a posture risk assessment needs to be done to determine the occupational risks face by the workers using the QEC method. The results show that only the washing station that categorized at the "safe" level while the other six stations are at level 3 which means it needs improvement because workers also have musculosceletal disorder in the upper body
\end{abstract}

Keywords : Awkward Posture, Musculoskeletal Disorder, NBM, QEC

\section{Pendahuluan}

Menurut Sutalaksana (seperti yang dikutip dalam Tarwaka et al., 2004), berdiri merupakan sikap siaga baik fisik maupun mental, sehingga aktivitas kerja yang dilakukan menjadi lebih cepat, kuat dan teliti. Pada dasarnya bekerja dengan posisi berdiri lebih melelahkan daripada duduk karena energi yang dikeluarkan lebih banyak 10-15\% dibandingkan dengan pekerjaan yang dilakukan dengan posisi duduk, apabila perkerjaan yang dilakukan dalam posisi berdiri harus dilakukan dalam periode yang lama, maka faktor kelelahan pekerja akan menjadi permasalahan.

IKM (Industri Kecil Menengah) Tahu Sari Murni merupakan salah satu industri pengolahan tahu yang terletak di Mojosongo, Surakarta. Industri yang dimiliki oleh Pak Aco Warso ini didirikan pada tahun 1984 dengan pekerja sebanyak 12 orang, yaitu sembilan orang bekerja di bagian produksi dan tiga orang lainya bekerja di bagian distribusi. Untuk mempertahankan rasa dan kualitas tahu yang dihasilkan, proses pembuatan tahu masih dilakukan secara manual dan tradisional. Walaupun proses penggilingan sudah dilakukan dengan bantuan mesin penggiling, namun untuk proses lainnya masih dilakukan secara manual. Proses pembuatan tahu meliputi: proses pencucian dan penggilingan kedelai, pemasakan dengan dipanaskan, penyaringan, pencetakan, pengepresan, serta pemotongan.

Berdasarkan pengamatan, IKM Tahu Sari Murni memproduksi rata-rata 250 loyang tahu dalam sehari. Aktivitas seluruh pekerja didominasi dengan postur kerja yang tidak alamiah seperti mengangkat, membungkuk, dan berdiri selama 7-8 jam. Bekerja dalam posisi berdiri akan memberikan tekanan dan beban statis pada otot, apabila posisi ini dilakukan dalam waktu yang lama, maka dapat menyebabkan gangguan 
fisik berupa kelelahan, keluhan pada sendi, otot atau tulang, pembengkakan, iritasi, termasuk munculnya gangguan yaitu musculoskeletal disorders (Supriyanto, 2011).

Hal ini dibuktikan dengan hasil wawancara dengan pekerja yang mayoritas menyatakan bahwa memiliki keluhan gangguan musculoskeletal di beberapa bagian tubuh, seperti bahu kanan, punggung, pergelangan tangan, serta bagian leher yang dirasakan setelah bekerja. Dengan kondisi pekerja yang telah diuraikan, maka perlu dilakukan penilaian postur kerja di IKM Tahu Sari Murni, agar dapat diketahui tingkat resiko yang dialami pekerja. Penilaian tingkat resiko pekerja dilakukan dengan menggunakan metode Quick Exposure Check (QEC) dan untuk mengetahui persentase dan keluhan pekerka mengenai bagian tubuh yang memilki gangguan musculoskeletal diketahui dengan menggunakan kuesioner Nordic Body Map.

\section{Metode Penelitian}

Adapun metodologi penelitian yang dilakukan dapat dilihat pada flowchart dengan penjelasan setiap langkah pada gambar berikut ini:

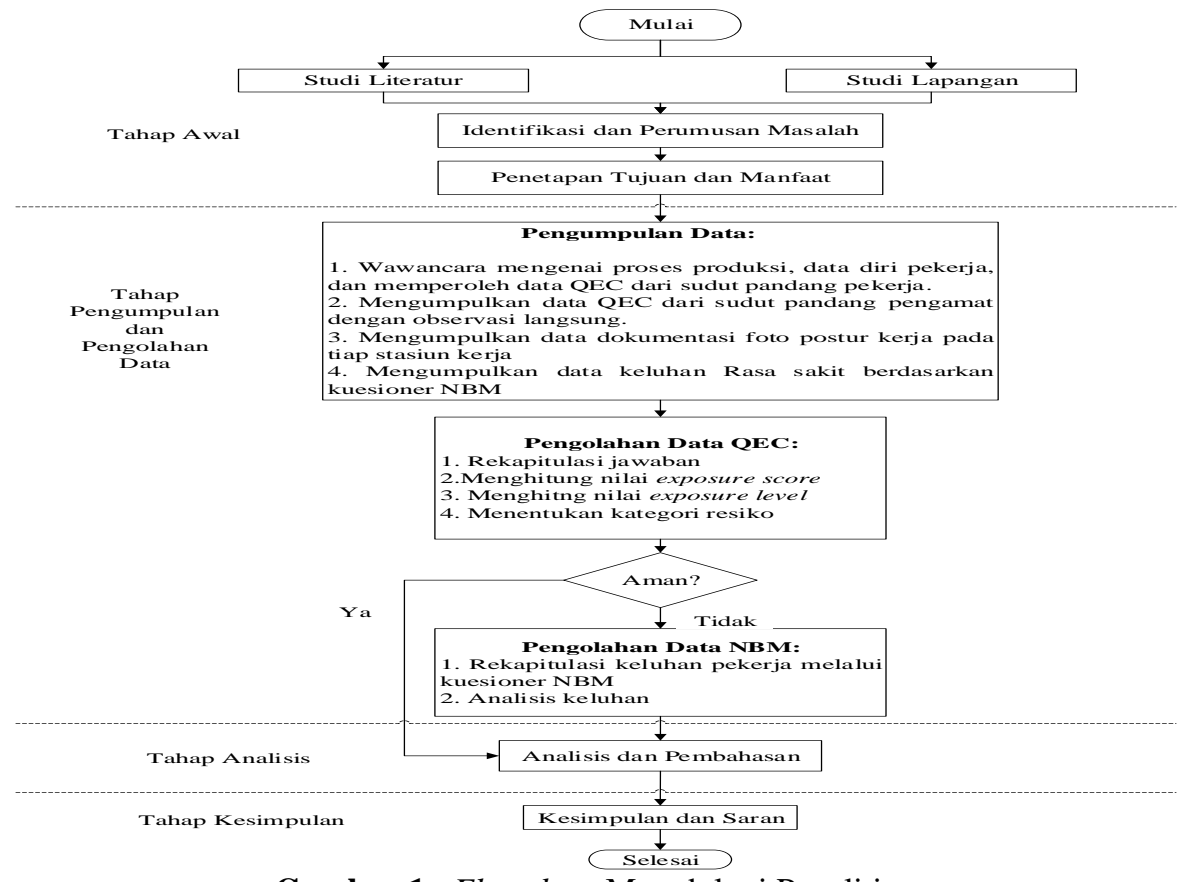

Gambar 1. Flowchart Metodologi Penelitian

Gambar 1 merupakan flowchart penelitian yang terdiri dari tahap identifikasi masalah, tahap pengumpulan dan pengolahan data, dan tahap analisis dan tahap kesimpulan. Berikut adalah uraian singkatnya.

Pada Tahap identifikasi masalah terdiri dari studi literatur, studi lapangan, identifikasi masalah dan perumusan masalah, serta penetapan tujuan penelitian dan manfaat penelitian. Tahap pengumpulan dan pengolahan data terdiri dari pengumpulan data berupa data pekerja, dokumentasi gambar dan video postur kerja operator, wawancara dan pengisian kuesioner QEC, serta wawancara dan pengisian kuesioner NBM untuk mengetahui keluhan yang dirasakan pekerja. Pada penelitian ini terdapat dua sumber data yang dikumpulkan, yaitu data primer dan sekunder. Data primer didapat dari pengambilan data secara observasi langsung dan wawancara dengan pihak perusahaan maupun dengan pekerja di IKM Tahu Sari Murni. Data tersebut meliputi data alur proses produksi tahu, data umum mengenai pekerja. Sedangkan data sekunder yang diperoleh yaitu data profil perusahaan, jumlah pekerja di bagian produksi yang dimiliki oleh IKM Tahu Sari Murni yang berjumlah 9 orang. Data yang dikumpulkan kemudian diolah menggunakan metode QEC dan metode REBA sehingga didapatkan nilai hasil yang menggambarkan kondisi saat ini. Selain itu kuesioner NBM juga dibagikan untuk diisi oleh pekerja agar dapat diketahui adakah keluhan-keluhan yang dirasakan oleh pekerja sebagai akibat dari pekerjaan yang dilakukan.

Pada Tahap Analisis, dilakukan analisa terhadap hasil dari pengolahan data yang sudah dilakukan, yaitu menganalisa kondisi awal, penilaian postur kerja melalui metode QEC dan menganalisa keluhan-keluhan yang dialami pekerja melalui kuesioner NBM, serta hasil perancangan fasilitas kerja sebagai usulan perbaikan dari masalah yang ada. Tahap terakhir yaitu tahap penarikan kesimpulan yang berisi kesimpulan akhir dari penelitian dan saran yang dapat diberikan berdasarkan penelitian yang dilakukan baik ke perusahaan maupun pada penelitian selanjutnya.

\section{Hasil dan Pembahasan}


Proses produksi tahu di IKM Tahu Sari Murni dilakukan dalam bangunan seluas $152 \mathrm{~m}^{2}$. Bangunan tersebut memiliki beberapa ruangan antara lain kantor, ruang tamu, gundang bahan baku, dapur, area produksi tahu, kamar mandi, area tungku pembakaran untuk menyalurkan uap panas, dan limbah. IKM Tahu Sari Murni memiliki sembilan karyawan yang bekerja di bagian produksi dan secara garis besar, proses produksi tahu meliputi tahapan-tahapan seperti yang ditampilkan pada gambar di bawah ini:

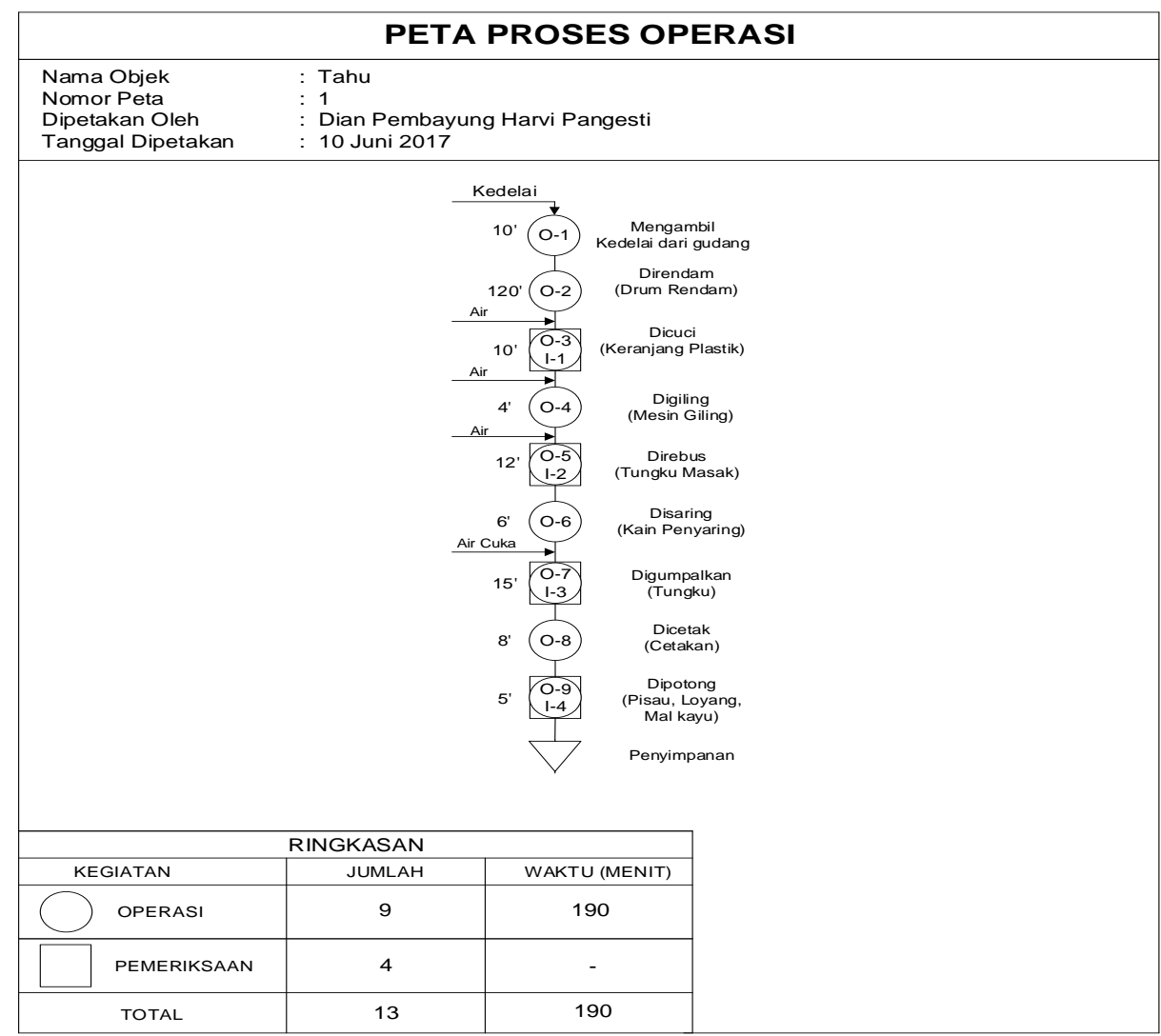

Gambar 1. Peta Proses Operasi Produksi Tahu

Identifikasi dan penilaian postur menggunakan kuesioner Quick Exposure Checklist (QEC) dilakukan pada sembilan pekerja dari tujuh stasiun produksi tahu di IKM Tahu Sari Murni sesuai dengan gambar proses produksi di atas. Kuesioner QEC diberikan kepada pekerja dan juga pengamat yang melihat bagaimana postur tubuh operator ketika bekeja. Kuesioner QEC untuk pengamat dan operator berbeda, akan tetapi keduanya digunakan untuk menganalisis kondisi suatu stasiun kerja. Contoh kuesioner pengamat dan pekerja yang digunakan dalam penelitian dapat dilihat pada Gambar 2. Setelah dilakukan penilaian baik penilaian melalui kuesioner pengamat dan kuesioner pekerja, maka dapat dibuat rekapitulasi jawaban dari kuesioner pengamat dan pekerja seperti yang ditampilkan tampak pada Tabel 2 dan Tabel 3. 

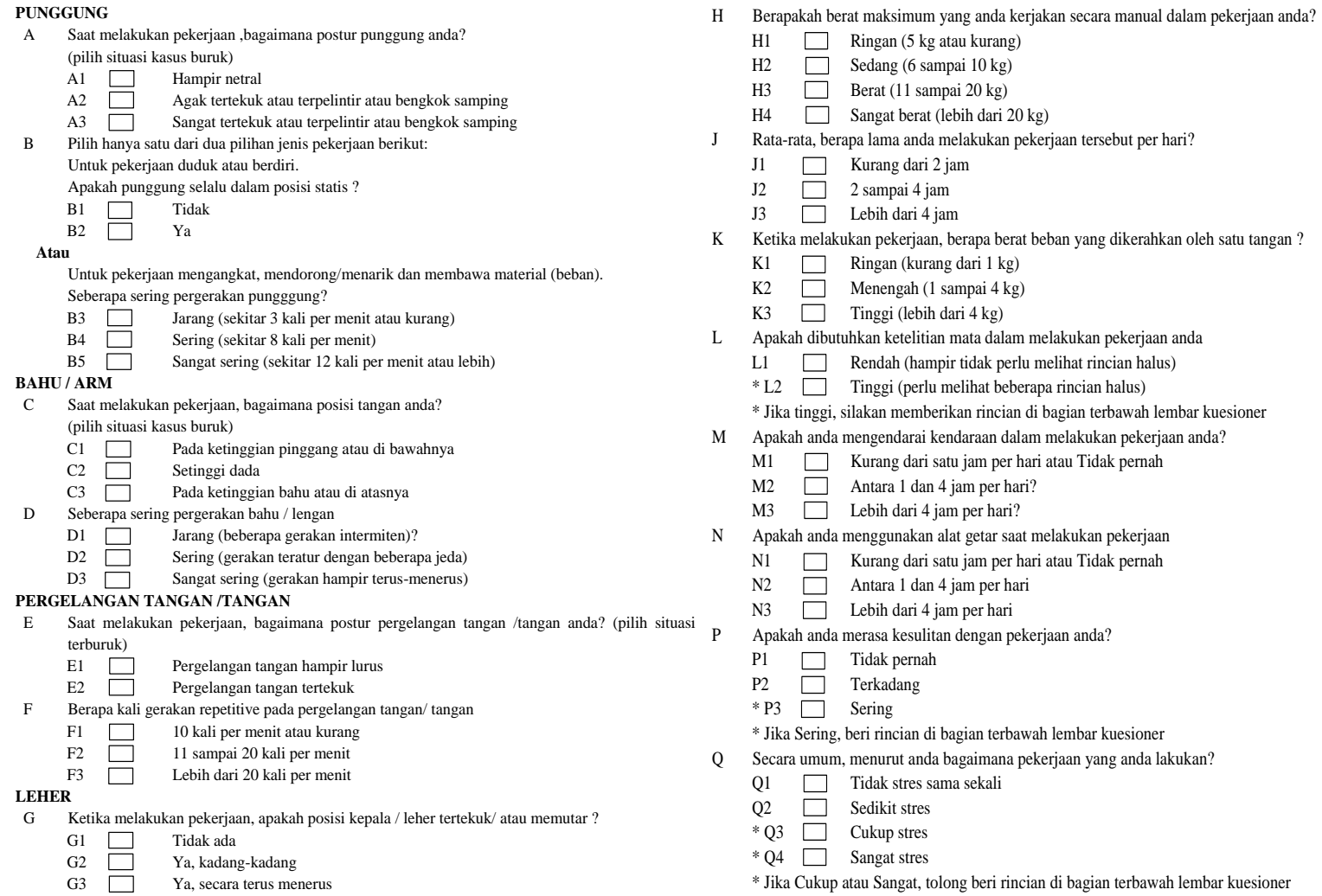

Gambar 2. Kuesioner QEC Pengamat dan Pekerja

Respon dari kuesioner QEC pengamat dan pekerja, berupa skor-skor dengan kode-kode yang ditetapkan sesuai dengan kategori jawaban atas pertanyaan yang ada pada kuesioner, dimana kategori tersebut dibagi menjadi dua hingga empat kategori dan pembagiannya berdasarkan tingkatan dari rendah ke tinggi. Berikut ini hasil rekapitulasi penilaian yaitu sebagai berikut:

Tabel 2. Rekapitulasi Penilaian Pengamat

\begin{tabular}{|l|c|c|c|c|c|c|c|}
\hline \multirow{2}{*}{\multicolumn{1}{c|}{ Stasiun }} & \multicolumn{7}{|c|}{ Pertanyaan } \\
\cline { 2 - 9 } & A & B & C & D & E & F & G \\
\hline Pencucian & A2 & B4 & C2 & D2 & E2 & F2 & G2 \\
\hline Penggilingan & A3 & B5 & C3 & D2 & E2 & F1 & G2 \\
\hline Perebusan & A3 & B4 & C2 & D2 & E2 & F1 & G2 \\
\hline Penyaringan & A3 & B5 & C3 & D3 & E2 & F3 & G2 \\
\hline Penggumpalan & A2 & B5 & C2 & D2 & E2 & F2 & G3 \\
\hline Pencetakan & A3 & B5 & C3 & D3 & E2 & F2 & G3 \\
\hline Pemotongan & A2 & B4 & C1 & D2 & E2 & F2 & G3 \\
\hline
\end{tabular}

Tabel 3. Rekapitulasi Penilaian Pekerja

\begin{tabular}{|l|c|c|c|c|c|c|c|c|}
\hline \multirow{2}{*}{\multicolumn{1}{c|}{ Stasiun }} & \multicolumn{7}{|c|}{ Pertanyaan } \\
\cline { 2 - 10 } & H & J & K & L & M & N & P & Q \\
\hline Pencucian & H1 & J1 & K2 & L1 & M1 & N1 & P1 & Q1 \\
\hline Penggilingan & H2 & J2 & K2 & L1 & M1 & N1 & P1 & Q1 \\
\hline Perebusan & H2 & J2 & K2 & L1 & M1 & N1 & P1 & Q1 \\
\hline Penyaringan & H3 & J1 & K3 & L1 & M1 & N1 & P1 & Q1 \\
\hline Penggumpalan & H1 & J2 & K2 & L1 & M1 & N1 & P1 & Q1 \\
\hline Pencetakan & H2 & J1 & K2 & L1 & M1 & N1 & P1 & Q1 \\
\hline Pemotongan & H2 & J3 & K1 & L1 & M1 & N1 & P1 & Q1 \\
\hline
\end{tabular}

Berdasarkan rekapitulasi penilaian pengamat dan penilaian pekerja, maka dapat dilakukan penentuan exposure score dengan menjumlahkan skor dari kombinasi penilaian pengamat dan pekerja pad tiap variabel. Penentuan exposure score dilakukan menggunakan scorelist yang melibatkan delapan variabel. Sebagai contoh, dibawah ini adalah scorelist penilaian exposure score pada stasiun pemotongan yang ditampilkan pada gambar 3: 

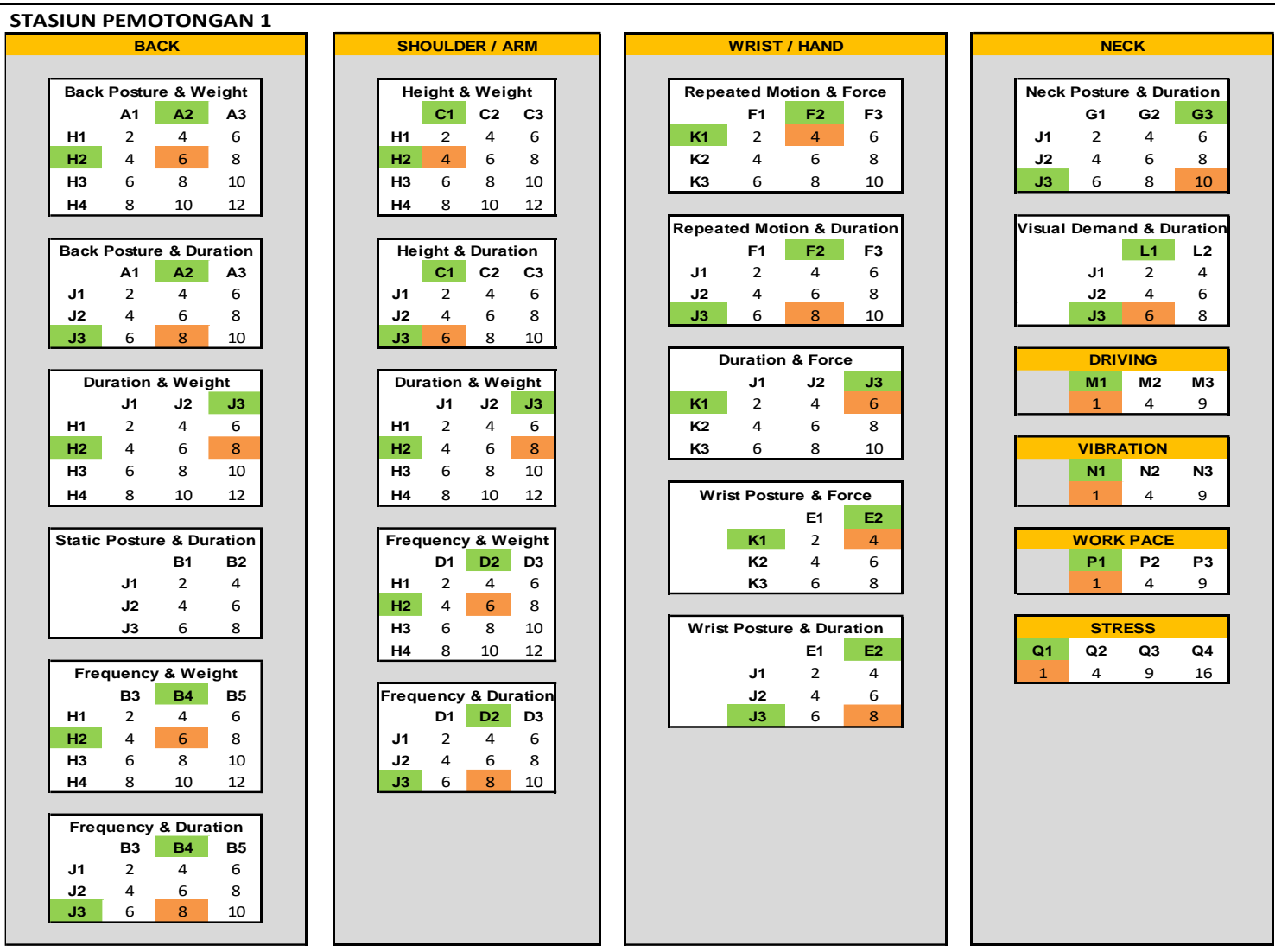

Gambar 3. Scorelist Penilaian Exposure Score

Langkah-langkah penentuan exposure score stasiun pemotongan pada scorelist di atas yaitu:

1. Variabel Punggung

Langkah 1: Interaksi postur punggung (A2) dengan baban $(\mathrm{H} 2)=6$

Langkah 2: Interaksi postur punggung (A2) dengan durasi (J3) $=8$

$=8$

Langkah 4: Interaksi frekuensi (B4) dengan beban kerja (H2) $\quad=6$

Langkah 5: Interaksi frekuensi (B4) dengan durasi (J3) $\quad=8$

$\begin{array}{ll}\text { Total score variabel punggung } & =36\end{array}$

2. Variabel Bahu

Langkah 6: Interaksi tinggi $(\mathrm{C} 1)$ dengan beban $(\mathrm{H} 2) \quad=4$

Langkah 7: Interaksi tinggi (C1) dengan durasi (J3) $\quad=6$

Langkah 8: Interaksi durasi (J3) dengan beban kerja $(\mathrm{H} 2) \quad=8$

Langkah 9: Interaksi frekuensi (D2) dengan beban kerja (H2) $\quad=6$

Langkah 10: Interaksi frekuensi (D2) dengan durasi (J3) $\quad=8$

Total score variabel bahu $\quad=32$

3. Variabel Tangan/Pergelangan Tangan

Langkah 11: Interaksi gerakan repetitif (F2) dengan gaya (K1) $=4$

Langkah 12: Interaksi gerakan repetitive (F2) dengan durasi (J3) $\quad=8$

Langkah 13: Interaksi durasi (J3) dengan gaya (K1) $\quad=6$

Langkah 14: Interaksi pergelangan tangan (E2) dengan gaya (K1) $=4$

Langkah 15: Interaksi pergelangan tangan (E2) dengan durasi (J3) $\quad=8$

Total score variabel pergelangan tangan $=\mathbf{3 0}$

4. Variabel Leher

Langkah 16: Interaksi postur leher (G3) dengan durasi (J3) $=10$

Langkah 17: Interaksi visual demand (L1) dengan durasi (J3) $\quad=6$

$\begin{array}{ll}\text { Total score variabel leher } & =16\end{array}$

5. Langkah $17:$ Driving/mengemudi (M) $=1$

6. Langkah $18:$ Vibration/getaran (N)

7. Langkah 19 : Tingkat kesulitan / Work pcae $(\mathrm{P}) \quad=1$

8. Langkah 20:Tingkat Stres (O) 
Berdasarkan contoh langkah-langkah penilaian exposure score pada stasiun pemotongan di atas, maka dapat ditentukan total skor QEC dengan menjumlahkan skor exposure dari tiap variabel yang dinilai pada stasiun pemotongan yaitu sebesar 118. Berikut ini rekapitulasi penilaian exposure score pada seluruh stasiun produksi tahu yaitu sebagai berikut:

Tabel 4. Rekapitulasi Exposure Score

\begin{tabular}{|l|c|c|c|c|c|c|c|c|c|}
\hline \multirow{2}{*}{ Stasiun } & \multicolumn{9}{|c|}{ Skor } \\
\cline { 2 - 11 } & Back & $\begin{array}{c}\text { Shoulder } \\
\text { /Arm }\end{array}$ & $\begin{array}{c}\text { Wrist/ } \\
\text { Hand }\end{array}$ & Neck & Drive & Vibration & $\begin{array}{l}\text { Work } \\
\text { pace }\end{array}$ & Stress & Total \\
\hline Pencucian & 18 & 18 & 24 & 6 & 1 & 1 & 1 & 1 & 70 \\
\hline Penggilingan & 38 & 34 & 26 & 10 & 1 & 1 & 1 & 1 & 112 \\
\hline Perebusan & 34 & 30 & 26 & 10 & 1 & 1 & 1 & 1 & 104 \\
\hline Penyaringan & 38 & 38 & 34 & 6 & 1 & 1 & 1 & 1 & 120 \\
\hline Penggumpalan & 28 & 24 & 30 & 12 & 1 & 1 & 1 & 1 & 98 \\
\hline Pencetakan & 32 & 32 & 28 & 12 & 1 & 1 & 1 & 1 & 108 \\
\hline Pemotongan & 36 & 32 & 30 & 16 & 1 & 1 & 1 & 1 & 118 \\
\hline
\end{tabular}

Setelah mengetahui nilai exposure score, maka tahap selanjutnya adalah menghitung nilai exposure level menggunakan rumus persamaan di bawah ini:

$$
E \%=\frac{x}{x_{\max }} x 100 \%
$$

Dengan:

$\mathrm{X}=$ Total skor yang diperoleh dari penilaian postur punggung, bahu/lengan, pergelangan tangan, dan leher pekerja.

$\mathrm{Xmax}=$ Total skor maksimum yang mungkin terjadi untuk postur punggung, bahu/lengan, pergelangan tangan, dan leher. Konstanta Xmax yang mungkin terjadi untuk pekerjaan statis adalah 162 dan untuk pekerjaan manual handling (mengangkat benda/menarik benda, membawa benda) nilai Xmax yang mungkin terjadi adalah 176.

Berdasarkan penghitungan dengan menggunakan persamaan (1), kemudian diperoleh nilai exposure level yang ditampilkan pada Tabel 5 yaitu sebagai berikut:

Tabel 5. Rekapitulasi Exposure Level

\begin{tabular}{|l|c|c|c|c|}
\hline \multicolumn{1}{|c|}{ Stasiun } & $\begin{array}{c}\text { Total } \\
\text { Score }\end{array}$ & E $(\%)$ & $\begin{array}{c}\text { Level } \\
\text { Tindakan }\end{array}$ & Kategori Tindakan \\
\hline Penyaringan & 120 & $68 \%$ & 3 & Tindakan dalam waktu dekat \\
\hline Pemotongan & 118 & $67 \%$ & 3 & Tindakan dalam waktu dekat \\
\hline Penggilingan & 112 & $64 \%$ & 3 & Tindakan dalam waktu dekat \\
\hline Pencetakan & 108 & $61 \%$ & 3 & Tindakan dalam waktu dekat \\
\hline Perebusan & 104 & $59 \%$ & 3 & Tindakan dalam waktu dekat \\
\hline Penggumpalan & 98 & $56 \%$ & 3 & Tindakan dalam waktu dekat \\
\hline Pencucian & 70 & $40 \%$ & 1 & Aman \\
\hline
\end{tabular}

Berdasarkan rekapitulasi nilai exposure level, dari seluruh stasiun hanya stasiun pencucian yang masuk dalam kategori aman, sedangkan stasiun lainnya masuk ke level tindakan 3 sehingga memerlukan adanya perbaikan dalam waktu dekat.

Data keluhan pekerja yang diperoleh berdasarkan kuesioner NBM yang diisi oleh sembilan orang pekerja di IKM Tahu Sari Murni menampilkan keluhan yang di persentasekan pada grafik di bawah ini: 


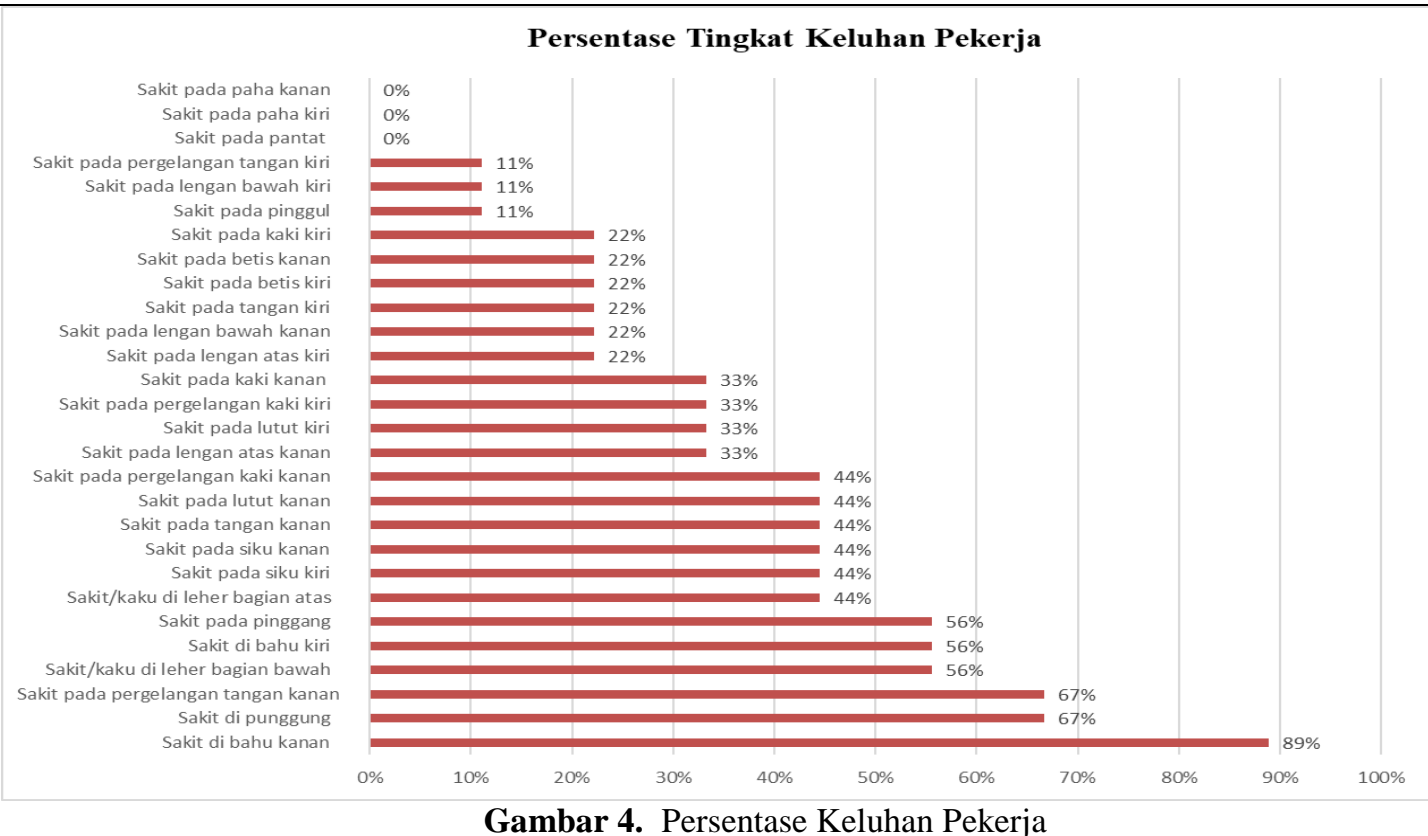

Berdasarkan grafik persentase keluhan di atas dapat dilihat jelas persentase keluhan yang dialami oleh pekerja di IKM Tahu Sari Murni mayoritas adalah sakit di tubuh bagian atas, seperti bahu kanan sebesar $89 \%$, punggung dan bahu kiri masing-masing sebesar $67 \%$, leher bagian atas serta sakit pada pergelangan tangan kanan.

\section{Simpulan}

Dari hasil penilaian menggunakan metode QEC pada seluruh stasiun produksi tahu di IKM Tahu Sari Murni, hanya stasiun pencucian yang masuk dalam kategori aman, sedangkan stasiun lainnya masuk ke level tindakan 3 sehingga memerlukan perbaikan dalam waktu dekat. Pekerja mengalami keluhan yang mayoritas berada pada tubuh bagian atas, seperti bahu kanan sebesar 89\%, punggung dan bahu kiri masing-masing sebesar $67 \%$, leher bagian atas serta sakit pada pergelangan tangan kanan.

Berdasarkan hasil dari penilaian QEC tersebut, maka diperlukan adanya perbaikan dalam waktu dekat sebagai upaya untuk mengurangi risiko yang dialami oleh pekerja serta mengurangi munculnya gangguan musculoskeletal pada pekerja. Perbaikan yang dapat dilakukan yaitu perubahan dan perbaikan terhadap metode kerja di IKM Tahu Sari Murni, mengadakan pelatihan secara berkala kepada pekerja agar dapat menerapkan cara kerja yang sesuai dengan kaidah ergonomi untuk mengurangi keluhan dan cedera akibat postur kerja yang salah.

\section{Daftar Pustaka}

Ilman, A,, Yuniar, \& Y., Helianty. (2013). Rancangan Perbaikan Sistem Kerja dengan Metode Quick Exposure Check (QEC) di Bengkel Sepatu X di Cibaduyut. Reka Integra, vol. 1, no. 2.

David, G., Woods, V., Li, G., \& Buckle, P. (2008). The Development of the Quick Exposure Check (QEC) for Assessing Exposure to Risk Factors for Work-Related Musculoskeletal Disorders. Applied Ergonomics, 39, 57-69. doi: 10.1016/j.apergo.2007.03.002

Definition and Domain of Ergonomics (n.d). Diakses pada Agustus 25, 2017, dari IEA. International Ergonomics Association website, http://www.iea.cc/

Li, G., \& Buckle, P., (1998). A Practical Method for the Assessment of Work-Related Musculoskeletal Risks - Quick Exposure Check (QEC). Proceedings of the Human Factors and Ergonomics Society 42nd Annual Meeting The Human Factors and Ergonomics Society US Santa Monica, 2, 1351-1355.

Supriyanto. (2011). Perancangan Postur Kerja pada Pekerja Bagian Pencucian dan Penggiligan Kedelai dengan Pendekatan Rapid Entire Body Assessment (REBA) untuk Mengurngi Resiko Musculoskeletal Disordersd (MSDS) Studi Kasus: Industri Kecil Pembuatan Tahu di Desa Banyuputih Salatiga. (Skripsi, Universitas Sebelas Maret)

Tarwaka, Bakri, S. H. A., \& Sudiajeng, L. (2004). Ergonomi untuk Keselamatan Kesehatan Kerja dan Produktivitas. Surakarta: Penerbit UNIBA Press. 